\title{
Palatal Rugae Pattern in Nepalese Subjects
}

\author{
Dr Dipshikha Bajracharya,' Dr Anisha Vaidya,' Dr Sunaina Thapa, ${ }^{3}$ Dr Sujita Shrestha \\ 'Lecturer, Dept of Oral Pathology \& Forensic Odontology, \\ .3Dental Surgeon, 4Lecturer, Dept of Community \& Public Health Dentistry \\ Kantipur Dental College, Kathmandu, Nepal
}

Correspondence: drdipshikhabaj@gmail.com

\section{ABSTRACT}

Objective: To determine the number and pattern of palatal rugae in Nepalese subjects and to find the association of gender with the number and pattern of palatal rugae.

Materials \& Method: 200 Nepalese subjects comprising of 100 male and 100 female were randomly selected and their maxillary casts were examined for the palatal rugae length applying the classification proposed by Thomas and Kotze and palatal rugae pattern was recorded using the classification given by Kapali. Statistical analysis using Student t-test was applied for comparing the number of palatal rugae between right and left sides. Chi square test was used to find the association between gender and number of rugae as well as the pattern.

Result: The study demonstrated that the mean number of primary palatal rugae on left side was predominant, similarly wavy pattern was the most predominant in Nepalese subjects. No statistical significant difference was noticed in the palatal rugae number and pattern between the gender groups.

Conclusion: The study found predominant palatal form in Nepalese subjects which might have superior effectiveness in population differentiation and may be used as an effective tool in forensic odontology identification.

Key words: forensic odontology, palatal rugae, pattern

\section{INTRODUCTION}

Human identification is based on scientific principles mainly involving fingerprints, dental records and DNA analysis. Use of fingerprints has some limitations in situations where the hands are charred or mutilated. Similarly DNA isolation may be expensive and technique sensitive hence, dental records provide durable evidence in post mortem identification. ${ }^{1,2}$ Like dentition, palatal rugae are considered unique to individuals as well as consistent in shape throughout life..$^{3,4}$

Palatal rugae are epithelial ridges on anterior part of palatal mucosa on each side of mid palatine raphe behind incisive papilla. These asymmetric ridges are well protected inside the oral cavity due to its anatomical position in incidents of trauma and incernation thereby providing an excellent post mortem details in human identification. The study of palatal rugae is called as Rugoscopy. Apart from other fields like anthropology; rugoscopy is used in the fields of dentistry like forensic odontology, prosthodontics and orthodontics. ${ }^{5}$ Various studies have shown significant difference in rugae pattern amongst the same and different races.4, 6,7

The present study was conducted among Nepalese subjects with regard to the number and pattern of palatal rugae since there are very few studies found in the literature. Also an attempt was made to show the association of gender with the number and pattern of palatal rugae.

\section{MATERIALS AND METHOD}

The present study was conducted in the Department of Oral Pathology and Forensic odontology in Kantipur Dental College Teaching Hospital and Research Center from December 2012 to July 2013. A total of 200 Nepalese subjects comprising of 100 male and 100 female of the age ranging from 16-30 years were chosen randomly and were included in the study. The study was conducted after obtaining institutional research committee (IRC) approval and informed verbal consent from the subjects. The exclusion criteria were the subjects with abnormalities of palate and lips, wearing partial dentures and those under orthodontic treatment.

Alginate impressions were made in perforated metal maxillary impression trays and dental stone casts were made. Black marker pen was used to delineate the outline of palatal rugae. Flexible brass wire and Vernier caliper of $0.01 \mathrm{~mm}$ accuracy were used to measure the length of rugae which was recorded according to the classification by Thomas and Kotze. ${ }^{4}$ Similarly the pattern of rugae was recorded using the classification given by Kapali et $a l^{8}$ (Figure 1). 


\section{Classification of palatal rugae}

Palatal rugae were classified based on their length and was determined by measuring its greatest dimensions regardless of its shape (Thomas and Kotze): ${ }^{4}$

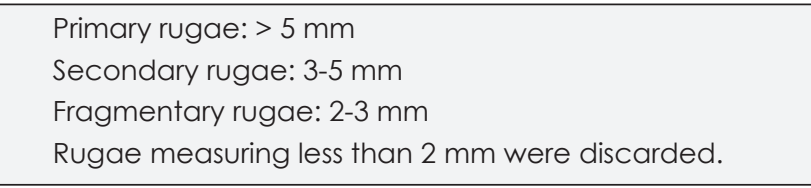

Shapes of individual palatal rugae were classified into five major types according to Kapali et $a^{8}$ as: curved, wavy, straight, circular and branched (Figure 1). The curved type had a simple crescent shape which curved gently. The wavy rugae were serpentine. Straight type ran directly from their origin to termination. Circular type had a definite continuous ring formation. Rugae which showed branching were classified under branched type.

All identification and measurements were performed by one examiner. The data thus obtained was documented in proforma and statistical analysis was done. Statistical analysis was done using SPSS 17.0 software. Comparison of the number of primary rugae between the right and left side was done using Independent Student t-test. Comparison was done for primary rugae form only because it was found predominantly. The association of gender with the number of rugae and pattern was tested using Chi-square test. The $p$-values were calculated under the predetermined level of significance of 0.05 at the confidence level of $95 \%$

\section{RESULT}

The age distribution of the subjects ranged from 1630 years with the mean of 21.25 years and standard deviation 2.79 (Table 1). Table 2 illustrates the descriptive statistics of the total number of rugae, where right primary rugae showed mean number of 3.82 whereas left primary rugae showed mean number of 3.85 . Similarly right and left secondary rugae showed mean number of 0.20 and 0.09 respectively. Fragmentary rugae showed mean number of 0.04 . There was no statistically significant difference between the number of primary rugae between right and left sides $(p=0.72)$ (Table 3$)$.
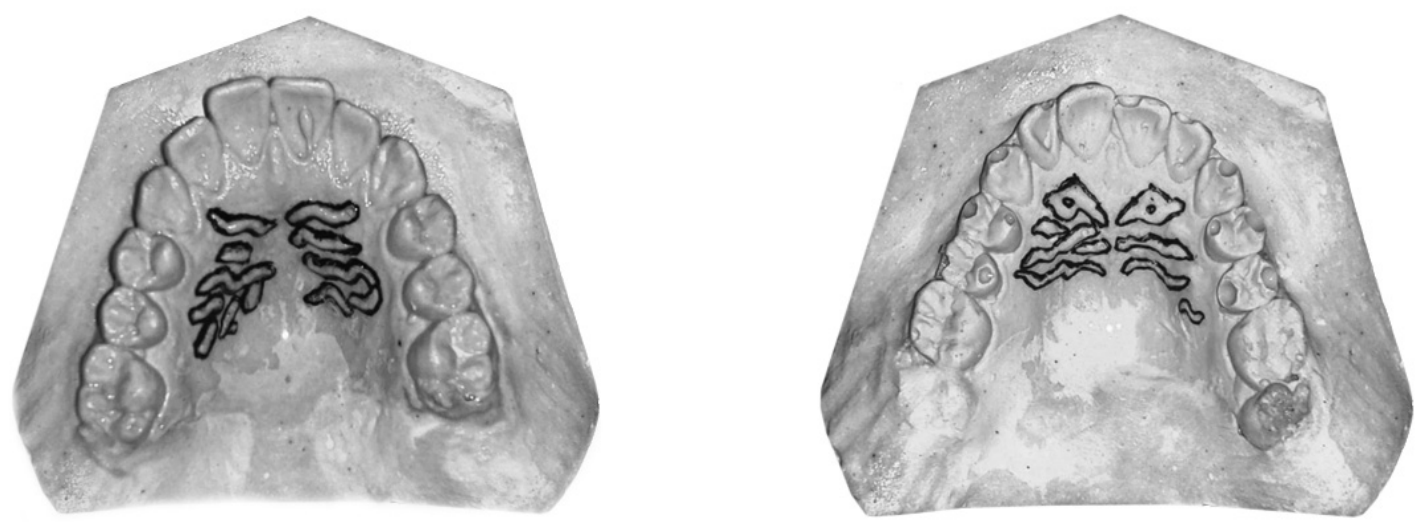

Figure 1- Palatal rugae pattern in cast model

Table 1: Age and gender distribution of the subjects

\begin{tabular}{|c|c|c|c|c|}
\hline Age (years) & Male & Female & Mean & \\
\hline $16-20$ & 38 & 56 & 21.25 & 2.78 \\
\hline $21-25$ & 47 & 41 & \\
\hline $26-30$ & 15 & 3 & \\
\hline Total & $\mathbf{1 0 0}$ & $\mathbf{1 0 0}$ & \\
\hline
\end{tabular}

Table 2: Frequency distribution of Palatal rugae length

\begin{tabular}{|l|c|c|c|c|c|c|}
\hline \multicolumn{1}{|c|}{ Rugae } & \multicolumn{3}{c|}{ Mean } & \multicolumn{2}{c|}{ SD } & \multicolumn{2}{c|}{ Range } \\
\hline & Right & Left & Right & Left & Left \\
\hline Primary & 3.82 & 3.85 & 0.89 & 0.87 & $1-7$ & $2-7$ \\
\hline Secondary & 0.20 & 0.09 & 0.49 & 0.39 & $0-3$ & $0-3$ \\
\hline Fragmentary & \multicolumn{2}{|c|}{0.04} & & 0.29 & & $0-3$ \\
\hline
\end{tabular}


Table 3: Comparison between Right and Left primary rugae

\begin{tabular}{|l|c|c|c|}
\hline \multicolumn{1}{|c|}{ Rugae } & Mean & SD & p-value \\
\hline Right primary & 3.83 & 0.89 & 0.72 \\
\hline Left primary & 3.85 & 0.87 & \multirow{2}{*}{} \\
\hline
\end{tabular}

NS - non significant

Mean number of right primary rugae in male was 3.93 and 3.72 in female. Likewise the mean number of left primary rugae was 4.03 in male and 3.67 in female (Table 4). Table 5 illustrates the frequency distribution of palatal rugae pattern ; where in wavy pattern was more predominant (mean 3.00) while circular (mean 0.22) was least amongst the sample. Similarly, other types were curved (mean 1.71), straight (mean 1.69) and branched (mean 1.06).

There was no statistically significant association between the gender groups and the number of palatal rugae as well as palatal pattern as shown in Table 6.

Table 4: Frequency distribution of Primary palatal rugae length and gender

\begin{tabular}{|c|c|c|c|c|c|c|}
\hline \multirow{2}{*}{ Rugae } & \multicolumn{2}{|c|}{ Number } & \multicolumn{2}{|c|}{ Mean } & \multicolumn{2}{|c|}{ SD } \\
\hline & Male & Female & Male & Female & Male & Female \\
\hline Right primary & 393 & 372 & 3.93 & 3.72 & 0.80 & 0.97 \\
\hline Left primary & 403 & 367 & 4.03 & 3.67 & 0.89 & 0.81 \\
\hline
\end{tabular}

Table 5: Frequency distribution of Palatal Rugae Shape

\begin{tabular}{|l|c|c|c|c|}
\hline \multicolumn{1}{|c|}{ Rugae shape } & N & Mean & SD & Range \\
\hline Curved & 200 & 1.71 & 1.48 & $0-8$ \\
\hline Wavy & 200 & 3.00 & 1.72 & $0-9$ \\
\hline Straight & 200 & 1.69 & 1.45 & $0-6$ \\
\hline Circular & 200 & .22 & .60 & $0-5$ \\
\hline Branched & 200 & 1.06 & 1.07 & $0-4$ \\
\hline
\end{tabular}

Table 6: Association of palatal rugae length and shape with gender

\begin{tabular}{|c|c|c|c|c|}
\hline \multirow{2}{*}{ Palatal rugae forms } & \multicolumn{2}{|c|}{ Total rugae number } & \multirow{2}{*}{$p$-value } & \multirow{2}{*}{ Significance } \\
\hline & Male & Female & & \\
\hline \multicolumn{5}{|l|}{ According to length } \\
\hline Primary & 796 & 739 & \multirow{3}{*}{0.175} & \multirow{3}{*}{ NS } \\
\hline Secondary & 17 & 40 & & \\
\hline Fragmentary & 0 & 8 & & \\
\hline \multicolumn{5}{|l|}{ According to shape } \\
\hline Curved & 116 & 226 & \multirow{5}{*}{0.147} & \multirow{5}{*}{ NS } \\
\hline Wavy & 378 & 221 & & \\
\hline Straight & 165 & 174 & & \\
\hline Circular & 21 & 22 & & \\
\hline Branched & 83 & 128 & & \\
\hline
\end{tabular}

NS - non significant 


\section{DISCUSSION}

Forensic odontology plays important role in identification of human remains. ${ }^{9}$ Palatal rugae has been studied for various reasons, most important one being personal identification. In the literature there is consensus opinion that palatal rugae remains fairly stable in number and do not undergo any change due to growth, ageing, tooth extraction and disease. ${ }^{5}$ Morphological changes may occur due to trauma, surgery, persistent pressure and proliferative benign and malignant lesions. ${ }^{5,} 10$

According to the present study, primary rugae were more predominant than secondary and fragmentary. Total number of primary rugae was more on left side compared to the right, however it was not statistically significant. The study done by Dohke and Kallianpur et al also proved left side of palatal rugae to be dominant, and explained it to be the phenomenon of regressive evolution. ${ }^{11,12}$

In our study the number of primary rugae did not show any statistical significant difference between the gender groups. Our finding was in accordance to the study by Kapali et al, ${ }^{8}$ which did not reveal any significant difference in the number of primary rugae between aboriginal Australian males and females. Our finding was also similar to Shetty et $a l,{ }^{13}$ wherein there was no significant difference in the number of rugae between the genders in Manglorean, Indian population. This observation was in contrast to Madan kumar et al: ${ }^{14}$ who reported significant difference in the number of rugae between the genders among Indian population of Chennai.
In our study wavy pattern was predominant followed by curved, straight, branched and circular. These findings were similar to study by Sathish Kumar et $a l,{ }^{15}$ in Puducherry, Indian population. The second most predominant pattern was curved which was in contrast to the finding by Kallianpur et $a:^{12}$ who reported straight type as second predominant pattern in Nepalese population. In our study there was no statistical significant difference in the rugae pattern between male and female Nepalese; which was in congruity with Sathish Kumar et $a^{15}$ and Bharath et ${ }^{15} .^{16}$ Thus certain rugae patterns are specific to particular population.

Though rugoscopy can be used in forensic identification, few studies have questioned this application in patients undergoing orthodontic treatment and in edentulous patients because of the chances of change in rugae pattern over a period of time in these patients. ${ }^{12,17}$ Nevertheless in patients undergoing orthodontic treatment changes in the length of the rugae have been reported while the pattern remains unchanged. ${ }^{10,12}$ Hence palatal rugae might be of immense help in identification of individuals in Forensic Odontology; provided both ante- and post-mortem details are available.

\section{CONCLUSION}

In the present study left primary palatal rugae was more in number similarly wavy pattern was most predominant in Nepalese subjects. No statistical significant difference was found in the rugae number and palatal rugae pattern of male and female. Since our study did not show any gender difference, the palatal rugae forms might have superior effectiveness in differentiating the ethnic groups.

\section{REFERENCES}

1. Whittaker DK. Introduction to forensic dentistry. Quintessence Int. 1994; 25(10):723-30.

2. Morlang WM. Forensic dentistry. Aviat Space Environ Med. 1982; 53(1):27-34

3. Lysell L. Plica palatinae transversae and papilla incisive in man: a morphological and genetic study. Acta Odontol Scand. 1955; 13(18):135-37.

4. Thomas CJ, Kotze T. The palatal rugae pattern: a new classification. J Dent Assoc S Afr. 1983; 38(3):153-57.

5. Caldas IM, Magalhães T, Afonso A. Establishing identity using cheiloscopy and palatoscopy. Forensic Sci Int. 2007; 165(1):1-9.

6. Shetty SK, Kalia S, Patil K, Mahima VG. Palatal rugae pattern in Mysorean and Tibetan populations. Indian J Dent Res. 2005 ; 16 (2):51-55.

7. Paliwal A, Wanjari S, Parwani R. Palatal rugoscopy: Establishing identity. J Forensic Dent Sci. 2010; 2(1):27-31.

8. Kapali S. Townsend G. Richards L. Parish T. Palatal rugae patterns in Australian aborigines and Caucasians. Aust Dent J. 1997; 42 (2):129-33.

9. Saraf A, Bedia S, Indurkar A, Degwekar S, Bhowate R. Rugae patterns as an adjunct to sex differentiation in forensic identification. J Forensic Odontostomatol.2011; 29(1): 14-19.

10. Bansode SC, Kulkarni MM. Importance of palatal rugae in individual identification. J Forensic Dent Sci. 2009; 1 (2):77-80.

11. Dohke M, Osato S. Morphological study of the palatal rugae rugae in Japanese 1. Bilateral differences in the regressive evaluation of the palatal rugae. Jap J Oral Biol. 1994; 36; 126-40.

12. Kallianpur S, Desai A, Kasetty S, Sudheendra U, Joshi P. An anthropometric analysis of facial height, arch length, and palatal rugae in the Indian and Nepalese population. J Forensic Dent Sci. 2011; 3(1): 33-37

13. Shetty M, Premalatha K. Study of palatal rugae pattern among the student population in Mangalore. J Indian Acad Forensic Med. 2011 : 33(2):1 12-15.

14. Madhankumar S, Natarajan S, Maheswari U, Anand V, Padmanabhan T and Fathima B. Palatal rugae pattern for gender identification among selected student population in Chennai, India. J Scientific Research Reports. 2013; 2(2): 491-96.

15. Kumar S, Vezhavendhan N, Shanthi V, Balaji N, Sumathi MK, Vendhan P. Palatal rugoscopy among Puducherry population. J Contemp Dent Pract. 2012; 13(3):401-4.

16. Bharath ST, Kumar GR, Dhanapal R, Saraswathi T. Sex determination by discriminant function analysis of palatal rugae from a population of coastal Andhra. J Forensic Dent Sci. 2011; 3(2):58-62.

17. Segelnick SL, Goldstein L. Forensic application of palatal rugae in dental identification Forensic examiner. 2005 ; 14 : 44-47. 